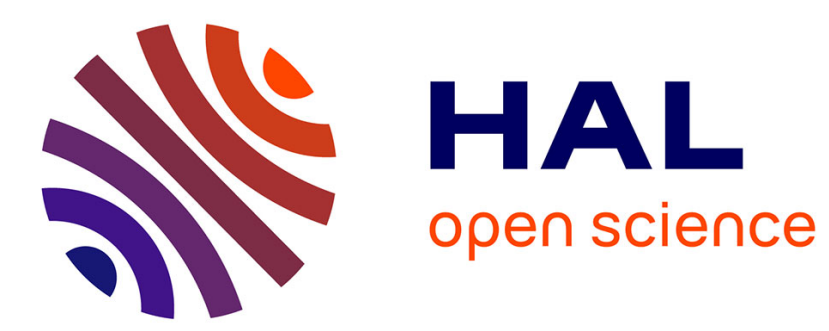

\title{
AN EXPERIMENT ON IMPACT PERFORATION OF URETHANE-FOAM SPONGE BY PROJECTILES
}

H. Yoshida

\section{To cite this version:}

H. Yoshida. AN EXPERIMENT ON IMPACT PERFORATION OF URETHANE-FOAM SPONGE BY PROJECTILES. Journal de Physique IV Proceedings, 1991, 01 (C3), pp.C3-265-C3-270. 10.1051/jp4:1991337 . jpa-00250479

\section{HAL Id: jpa-00250479 https://hal.science/jpa-00250479}

Submitted on 1 Jan 1991

HAL is a multi-disciplinary open access archive for the deposit and dissemination of scientific research documents, whether they are published or not. The documents may come from teaching and research institutions in France or abroad, or from public or private research centers.
L'archive ouverte pluridisciplinaire HAL, est destinée au dépôt et à la diffusion de documents scientifiques de niveau recherche, publiés ou non, émanant des établissements d'enseignement et de recherche français ou étrangers, des laboratoires publics ou privés. 
Colloque C3, suppl. au Journal de Physique III, Vol. 1, octobre 1991

\title{
AN EXPERIMENT ON IMPACT PERFORATION OF URETHANE-FOAM SPONGE BY PROJECTILES
}

\author{
H. YOSHIDA \\ Mechanical Engineering Laboratory. Agency of Industrial \\ Science and Technology, 1-2 Namiki, Tsukuba 305, Japan
}

\begin{abstract}
Résumé : En utilisant des projectiles lancés par un canon à air comprimé, des essais de perforation sur un bloc de mousse d'urethane on été réalisés. On montre que la précision du résultat obtenu (au sens de l'usinage) est bien meilleure que celle obtenue par les méthodes classiques de perçage au foret ou utilisant le faisceau d'un laser YAG. Pendant la perforation, on observe la formation d'un bouchon, comme cela a d'abord été observé pour les matériaux métalliques. Ceci implique une similarité entre ces deux types de matériau vis à vis de la formation dynamique d'un bouchon pendant la perforation.

Abstract-By using projectiles launched by a pneumatic gun, impact perforation test of urethane-foam sponge has been carried out. Precise perforation of this material by the impact projectile is found to be possible, while conventional methods of YAG laser beam and drill cannot perforate it accurately. During the perforation process, plug formation phenomenon, which was originally observed in metallic material, is also observed in the present urethane-foam sponge. This implies existance of a dynamic similarity on the plug formation phenomena between two materials.
\end{abstract}

\section{1.-Introduction.}

Impact perforation phenomenon is one of the most important subjects in evaluating transient behavior of materials under impulsive loading and has been extensively discussed in the literature $/ 1 /$. Most of the previous investigations, however, are concerning with the impact against metallic targets /1-3/. For other materials, such as high polymers for instance, investigation on the impact phenomena has been very limited $/ 4 /$ and, hence, the information about the impact perforation seems to be insufficient. Recently, as a method of drill machining of nonmetallic, soft materials, the impact perforation by projectiles has been tested $/ 5,6 /$. The method of impact perforation has two obvious features: 1) because of the impulsive loading, area of influence of the stress waves can be confined during the perforation process and 2) high energy density can be obtained if we use small projectiles with high impact velocity. These features are advantageous for process of precise drill machining.

We have studied impact perforation behavior of vinyle chloride sheet $/ 5 /$ in order to obtain information about possibility of the drilling tecnique for high polymers. In the present paper we introduce the experimental results of impact perforation of urethane-foam sponge. The thickness of the target ranges from $1 \mathrm{~cm}$ to $15 \mathrm{~cm}$. The impact velocities are $60 \mathrm{~m} / \mathrm{s}-450 \mathrm{~m} / \mathrm{s}$.

\section{2.-Experimental.}

The projectile is flat-ended cylindrical shape with $3.9 \mathrm{~mm}$ diameter,10 mm long, $0.15 \mathrm{~g}$ weight and made of bakelite. It is launched by a pneumatic gun $/ 5 /$. This 
facility is illustrated schematically in Fig.1. In order to facilitate repeat launch, a quick-acting valve system newly developed is used in the high pressure chamber $/ 5 /$. The projectile is set at the launch tube breech. The launch tube is $4 \mathrm{~mm}$ inside diameter, $1 \mathrm{~mm}$ thick, $1.5 \mathrm{~m}$ long and made of copper. To avoid bending of the launch tube, the tube is placed coaxially inside the rigid stainless steel pipe through cylindrical spacers. The spacers are merely used to adjust the outside and inside diameters of the launch tube and the stainless steel pipe.

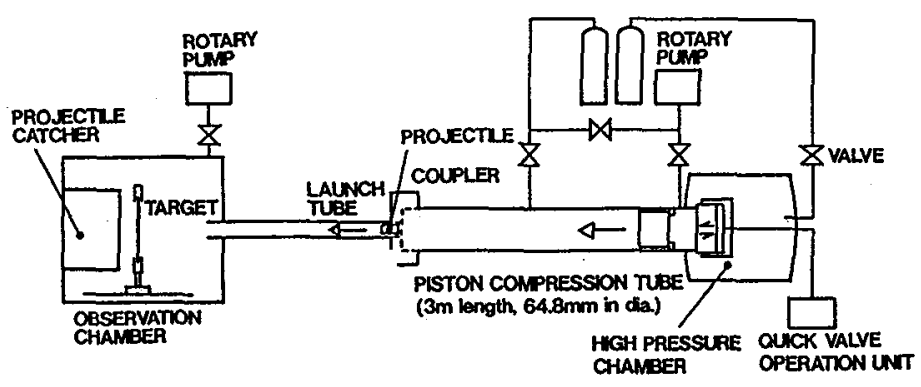

Fig.1 Schematic diagram of the pneumatic gun.

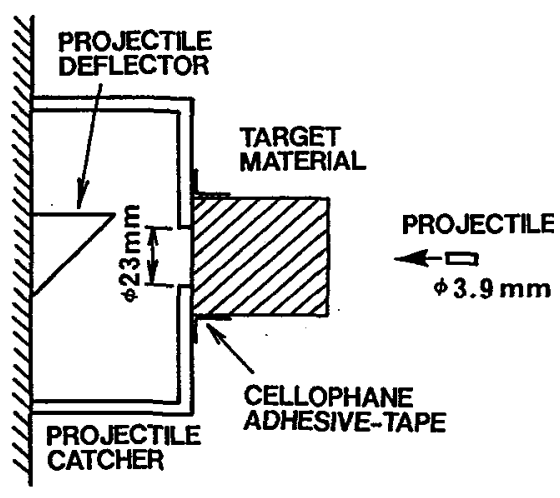

Fig.2 Projectile catcher and target support.

In a series of the experiment, the observation chamber and piston compression tube are filled with atmospheric air. Bottled nitrogen is used as driver gas in the high pressure chamber. The incident velocity of the projectile is determined by measuring the traverse time between two He-Ne laser beams of diameter $2 \mathrm{~mm}$ placed $80 \mathrm{~mm}$ and 135 mm downstream of the launch tube muzzle. The target material is set on the front surface of the projectile catcher by using the cellophane adhesive tape. Situation of the target support is shown in Fig.2.

\section{3.-Results and discussion.}

Figure 3 shows typical penetration modes of urethane-foam sponge impacted by the 
bakelite projectiles with various incident velocities. The density and velocity of sound wave propagation of the sponge used are measured to be $0.0265 \mathrm{~g} / \mathrm{cm}^{3}$ and about $100 \mathrm{~m} / \mathrm{s}$, respectively. The velocity of sound wave was evaluated based on the Young's modulus and the density of the sponge, both of which were measured in our laboratory. Photograph 1 shows the perforated target and its plug-like chip removed by the impact projectile with incident velocity of $230 \mathrm{~m} / \mathrm{s}$. As can be seen in this photograph length of the chip is somewhat larger than the target thickness. This elongation is supposed to be due to reduction of residual stress inside the chip, which appears after the chip is removed by the projectile. It is reasonable to consider that some residual stress is probably generated during manufacturing process of the urethane-foam sponge. We also see that perforation by the projectile is perfect, though diameter of the chip slightly increases along the projectile path from incident side to exit side. This increase of the chip diameter is considered to be closely related to the velocity of the projectile inside the target material. The energy required for the above perforation is estimated to be less than $4 \mathrm{~J}$, which is the measured kinetic energy of the incident projectile. The penetration mechanism of the above phenomena is now under study and we leave a detailed discussion about this for another opportunity.

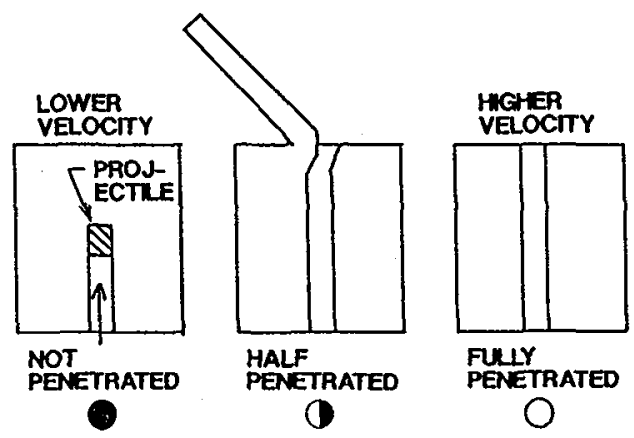

Fig.3 Typical penetration modes.

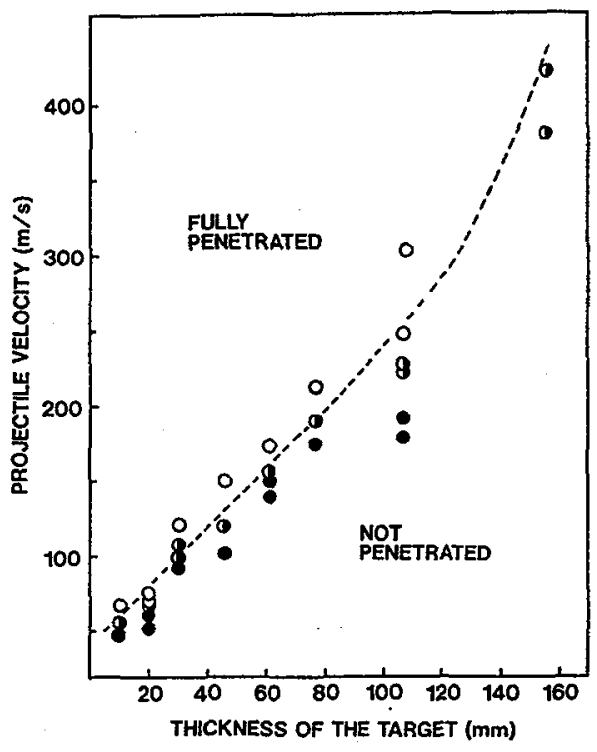

Fig.4 Impact projectile velocity vs. target thickness. 
We also made perforation tests of the same urethane-foam sponge used here by using a YAG laser beam (wave length $=1.06 \mu \mathrm{m}$ ) and drill. When we used the laser beam, it ablated the sponge surface to make only a bowl-shaped cavity and could not penetrate the target even with the input energy of more than $50 \mathrm{~J}$ (Photo. 2(c)). In the experiment the laser beam was irradiated impulsively by several shots. Duration of the single irradiation pulse is 5 to $10 \mathrm{~ms}$ and the average energy of it is 20 to 50 $J$. Note that the input energy of the laser beam is much more greater than that of the projectile $(4 \mathrm{~J})$. Recently, the ablation of polymers by excimer laser is also reported in Ref./7/. On the other hand, when we used the drill, it surely penetrated the target material. However, after pulling out the drill, fibrous chips refilled the perforated hole. In other words, perforation is not perfect. The results of perforation by the projectile, drill, and laser are compared in Photo. 2. In the case of Photo. $2(a)$ and (b) the sponge is illuminated from the rear side to show the state of perforation. Perforation by drill is not perfect as mentioned above and you cannot see through the hole clearly ((b)). In the case of (c) larger ablation traces are for the surface painted with black ink, while the smaller ones are for that without the ink.

Figure 4 shows the impact velocity for various penetration modes (defined in Fig.3) as a function of thickness of the target. The dotted line drawn in this figure roughly indicates the limit, above which full perforation is possible. In the region of full perforation (region of "fully penetrated" in Fig.4) plug formation phenomenon /8/ apppears. Generally speaking, in this figure the impact velocity for full perforation is roughly proportional to the the thickness of the target up to about $80 \mathrm{~mm}$. However, it should be pointed out that this dotted line does not seem to intersect the zero-velocity at 0 mm thickness. This result suggests existance of the lowest impact velocity required for the process of plug formation. At present, by considering the present target material as an ordinary spring-dashpot system with constant elasticity and viscosity, it is found that the travel distance of the projectile from the target surface (i.e. the point of incidence) to the point it stops inside the target is proportional to the impact velocity $/ 9 /$. In the present experiment only projectiles of circular cross section are used. The case of square cross section of $10 \mathrm{~mm} \times 10 \mathrm{~mm}$ is tested under the atmospheric condition in Ishikawajimaharima Heavy Industries (IHI) $/ 10 /$. In their experiment, by using Electro-Thermal (ET) Gun, polycarbonate projectile was impacted into the urethane foam target of 5 $\mathrm{cm}$ thick at the incident velocity of $2.5 \mathrm{~km} / \mathrm{s}$. Similar to the case of circular cross section, the same square cross section with the projectile was perforated in the target. The perforation geometry in the target was somewhat disturbed at the exit side $/ 10 /$. This is considered to be partly due to the support system of the target.

So $f a r$ we have discussed about the impact perforation of a high polymer material, such as urethane foam. In the present target material plug formation is observed in the incident velocities higher than about $60 \mathrm{~m} / \mathrm{s}$. Regarding a metallic material the plug formation appears in the incident velocities above $1 \mathrm{~km} / \mathrm{s} / 8 /$. Such a remarkable difference in initiation velocity of the plug formation is probably reduced to remarkable difference in the propagation velocity of stress waves (i.e. velocity of sound wave) between a high polymer and metal. In the plug formation phenomenon sound velocity of the target material seems to be one of key parameters. By comparing the plug formation phenomena of two typical materials above mentioned a certain dynamic similarity seems to underlie between them.

\section{4.-Concluding remarks .}

By using projectiles launched by a pneumatic gun, impact perforation test of urethane-foam sponge (density $=0.0265 \mathrm{~g} / \mathrm{cm}^{3}$, velocity of sound wave = about $100 \mathrm{~m} / \mathrm{s}$ ) has been carried out. As a result, precise perforation of this material by impact projectiles is found to be possible, while the typical, conventional perforation methods by YAG laser beam and drills cannot perforate it accurately. Within the present impact velocities $(<450 \mathrm{~m} / \mathrm{s})$, perforation of the urethane-foam sponge is possible for the thicknesses up to about $15 \mathrm{~cm}$. For the thicknesses up to $80 \mathrm{~mm}$ the 
thickness of full perforation is roughly proportional to the impact velocity of the projectile. This result is similar to that predicted by the simple visco-elastic model $/ 9 /$.

Moreover, the plug formation phenonenon, which was originally observed in metal plates, is also observed in the present experiments on urethane-foam sponge for incident velocities above $60 \mathrm{~m} / \mathrm{s}$. (The velocity of $60 \mathrm{~m} / \mathrm{s}$ may not be exactly the lowest limit for the plug formation.) This fact implies existance of a dynamic similarity rule on the plug formation phenomena between the urethane foam and metal. In this paper only experimental results have been discussed; analysis for precise mechanism of the perforation is now under study and will be published elsewhere.

The author wishes to thank my colleagues Dr.T. Koda for his advice and Messrs. Y.Usui, H.Ogiso and S.Nakano for their help during the experiment and preparation of the manuscript.

\section{References}

/1/ J.A.Zukas, et al., Impact dynamics (J.Wiley, New York, 1982).

/2/ S.T.Jenq, W.Goldsmith and J.M.Kelly, Int. J.Solids.Struct., 24,1243 (1988).

/3/ J.Liss and W.Goldsmith, Int. J. Impact Engn'g. 2, 37 (1984).

/4/ J.P.Dear, J.Appl. Phys. 67, 4304 (1990).

/5/ H.Yoshida and Y.Hoshi, Theo. Appl.Mech. (Univ. Tokyo Press) 39,169 (1990).

/6/ H.Yoshida,Y.Hoshi, and S.0gawa, Proc.J.S.M.E. (No.900-59 B)183(1990) (in Japanese)

/7/ P.L.G.Ventzek, et al., J. Appl. Phys. 68, 965 (1990).

/8/ N.Cristescu, Dynamic Plasticity, North-Holland pub.,Amsterdam (1967).

/9/ H.Yoshida, unpublished.

/10/ K. Uematsu, private communication. 


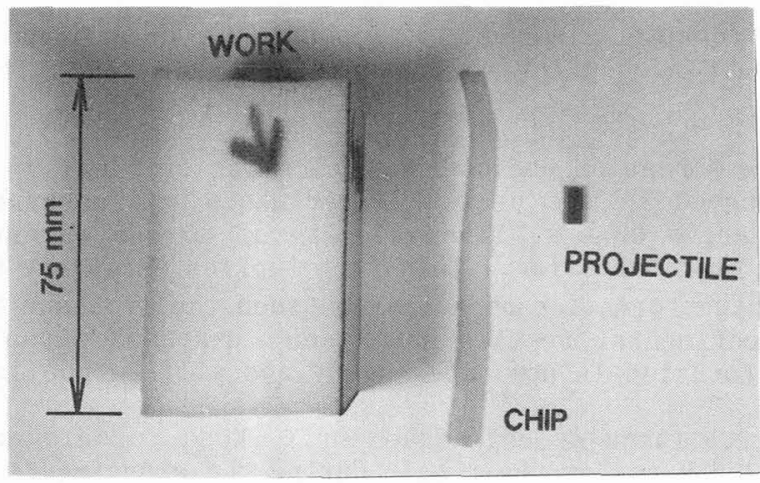

Photo.1 Plug formation by the projectile.



Photo.2(a)

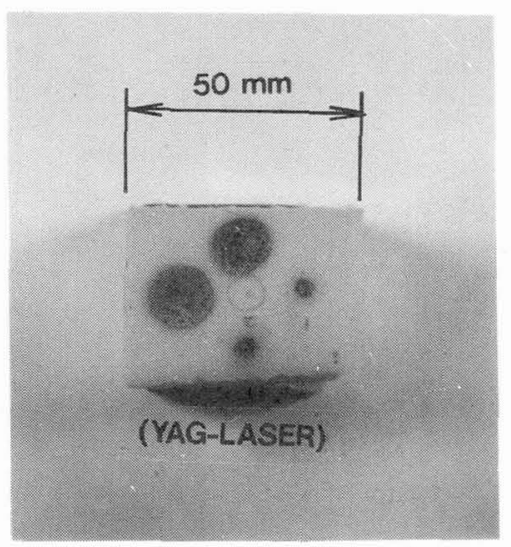

Photo.2(c)

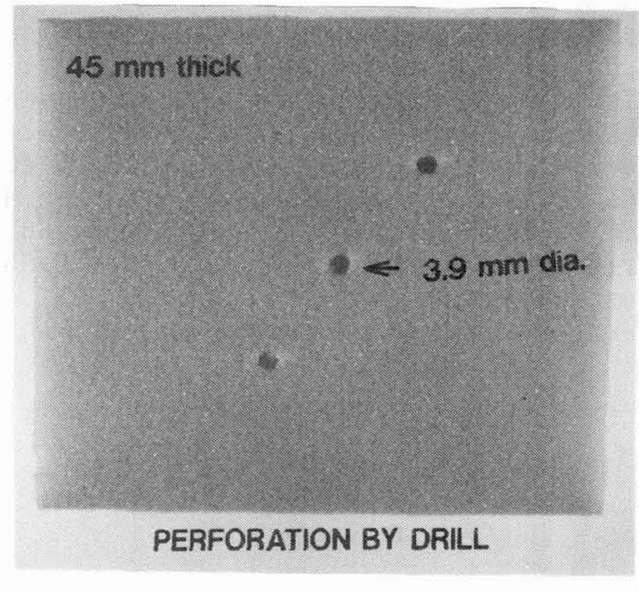

Photo.2(b)

Photo.2 Penetration of urethane-foam sponge by (a)projectile, (b)drill, and (c)YAG laser (larger ablation traces are for the surface painted with black ink, while smaller ones are for that without the ink). In the cases of (a) and (b) the sponge is illuminated from the rear side to show the state of the perforation. In the case of (b) perforation is not complete and you cannot see through the perforation clearly. 